\title{
'We ARE THE FORGOTTEN ONES': OCCUPATIONAL STRESS AMONG UNIVERSITY SECRETARIES IN BOTSWANA
}

\section{Authors:}

Ilse E. Plattner ${ }^{1}$

Diana S. Mberengwa ${ }^{1}$

\section{Affiliations:}

${ }^{1}$ Department of Psychology,

Faculty of Social Sciences,

University of Botswana,

Botswana

\section{Correspondence to:}

Ilse Plattner

email:

plattner@mopipi.ub.bw

\section{Postal address:}

Department of Psychology, Faculty of Social Sciences,

University of Botswana,

Private Bag 00705,

Gaborone, Botswana

\section{Keywords:}

human resource management; organisational psychology; psycho-physiological wellbeing; secretarial profession; stress management

\section{Dates:}

Received: 01 May 2009

Accepted: 15 July 2010

Published: 26 Oct. 2010

\section{How to cite this article:}

Plattner, I.E., \&

Mberengwa, D.S. (2010).

'We are the forgotten ones': Occupational stress among university secretaries in Botswana. SA Journal of Human Resource Management/SA Tydskrif vir Menslikehulpbronbestuur, 8(1), Art. \#213, 8 pages. DOI: 10.4102/sajhrm.v8i1.213

\section{This article is available} at:

http://www.sajhrm.co.za

\section{(C) 2010. The Authors.}

Licensee: OpenJournals Publishing. This work is licensed under the Creative Commons Attribution License.

\begin{abstract}
Orientation: Secretaries play an essential role in any work organisation, but their contributions and support in the daily management activities are not always recognised.
\end{abstract}

Research purpose: There is little research on occupational stress among secretaries. Therefore, this study aimed to investigate work-related stressors in the secretarial profession and their association with psychosomatic complaints.

Motivations for study: Considering the lack of research on secretaries, it was the objective of this study to investigate occupational stressors in the secretarial profession and their association with psycho-physiological wellbeing.

Research design, approach and method: Sixty-four secretaries at the University of Botswana participated in the study (response rate: $43.8 \%$ ). Data were gathered through a self-administered questionnaire. Correlational analyses were performed using Spearman's rho.

Main findings: Seventeen potential stressors were identified, referring to lack of job clarity, performing work outside one's job description, reduced competencies, supervisors who perform secretarial work, sharing resources such as an office or a telephone, lack of recognition and limited opportunities for promotion. Most stressors correlated significantly with one or more psychosomatic complaints.

Practical/managerial implications: Additional research would be necessary to compare various work contexts and organisation-specific work environments and to investigate their relevance to occupational stress and health among secretaries.

Contribution/value-add: The results of the study could be of use for human resource managers, as well as for supervisors of secretaries, in order to minimise potential stressors that could negatively affect the health of secretaries.

\section{INTRODUCTION}

Work-related stress was once thought of as occurring only in those who work in senior positions; it is now acknowledged that occupational stress can be experienced by employees at every level (Williams, 2003). In fact, stress is much more common in employees at lower levels of workplace hierarchies (Williams, 2003), where they have less control over their work situation. More recently, studies have targeted occupational stress in various professions, such as nurses, doctors, police officers, teachers, managers and academics (e.g. Barkhuizen \& Rothmann, 2008; Cottrell, 2001; Hendel \& Horn, 2008; Lindorff, 2000; Oginska-Bulik, 2005; Ortega, Brenner \& Leather, 2007; Peltzer, Mashego \& Mabeba, 2003; Tytherleigh, Jacobs, Webb, Ricketts \& Cooper, 2007; Williams, 2003; Zurlo, Pes \& Cooper, 2007), but little research has been conducted on occupational stress among secretaries. While secretaries may have been included in some studies that investigated occupational stress among 'support staff' (e.g. Jacobs, Tytherleigh, Webb \& Cooper, 2007), not much literature focuses on the secretarial profession.

Secretaries play an essential role in any work organisation, but their contributions and support in the daily management activities are not always recognised (Demongeot, 1986; Flam, 2002). Often, secretaries perform highly demanding tasks but have minimal control over job conditions, which makes them prone to occupational stress (Snow, Swan, Raghavan, Connell \& Klein, 2003). It has been documented that the degree of control that employees have determines whether they experience stress and how they cope with it (Clarke \& Cooper, 2000; Peeters, Buunk \& Schaufeli, 1995; Spector, 2003). The few studies that investigated secretaries identified lack of control, increasing demands, lack of recognition and interpersonal frustration caused by colleagues and supervisors as typical stressors for secretaries (Herrting, Nilsson, Theorell \& Larsson, 2003; Michailidis \& Asimenos, 2001; Peeters et al., 1995; Snow et al., 2003). Generally, work-related stress affects employees negatively in their fulfilment and functioning at work (Farmer, Clancy, Oyefeso \& Rassool, 2002), which often results in feelings of dissatisfaction with their achievements and in unhappiness (e.g. Hardy, Woods \& Wall, 2003; Michailidis \& Asimenos, 2001). Various studies have also identified occupational stress as a predictor of the burnout syndrome (e.g. Dickinson \& Wright, 2008; Malach-Pines, 2005; Peltzer et al., 2003; Van Dierendonck, Garssen \& Visser, 2005).

Occupational stress lowers productivity (Adams \& Cowen, 2004; Stein, 2001) and has a negative effect on job satisfaction and organisational commitment (Ortega et al., 2007; Stacciarini \& Troccoli, 2004). Often, stress and its various effects are intertwined. Snow et al. (2003) observed that secretaries who reported work pressure were more likely to suffer from depression, anxiety and somatic symptoms. Garrison and Eaton (1992) established that work-related stress among secretaries, combined with job dissatisfaction, led to higher levels of absenteeism. Absenteeism can result from stressful conditions 
and related illnesses (Adams \& Cowen, 2004; Hardy et al., 2003), but absenteeism can also be a way of coping with stressful working conditions, as absence from work was found to relieve stress (Furnham, 2005). Snow et al. (2003) found that high levels of stress among secretaries were associated with avoidant-style coping behaviour rather than with active coping strategies. In the same study, avoidance coping was also related more significantly to negative psychological outcomes. Herrting et al (2003) found that secretaries used professional pride as a way of coping with stressors, such as lack of recognition.

Although occupational stress is regarded as 'normal' and inevitable in working life (Harkness et al., 2005), job stress can interfere with physiological wellbeing. Occupational stress is known to contribute to physical illness (e.g. coronary heart disease) and somatic symptoms, such as headaches, back pain, high blood pressure, fatigue and insomnia (Akerstedt et al., 2002; Sadeh, Keinan \& Daon, 2004; Stein, 2001); it negatively affects the immune system and even increases the occurrence of the common cold (Boscolo, Youinou, Theoharides, Cerulli \& Conti, 2008; Halpern, 2005; Segerstrom \& Miller, 2004). Subsequently, occupational stress leads to health and economic costs that make stress management at the workplace important (Murta, Sanderson \& Oldenburg, 2008; Noblet \& LaMontagne, 2006). Over the years, work organisations have introduced health promotion and wellness programmes as part of stress management interventions (Noblet \& LaMontagne, 2006). However, the effectiveness of such programmes has been questioned as they mainly target the individual employees and their ways of coping with stressful conditions, rather than the causes of stress that are inherent to the workplace or the kind of work that people do (Murta et al., 2008).

Considering the lack of research on secretaries, it was the objective of this study to investigate occupational stressors in the secretarial profession and their association with psychophysiological wellbeing. More specifically, the study aimed to explore work-related stressors that might be typical of the secretarial profession, whether the presence of such stressors is associated with the psychosomatic complaints of secretaries and whether the subjective stress experience compared to the mere exposure to potential stressors makes a difference in the psychosomatic complaints. The target group was secretaries at the University of Botswana, which is one of the biggest employers in Botswana and has about 150 positions for secretaries. As far as the authors of this study could ascertain, no study on occupational stress has been conducted with secretaries in the Botswana work context. The results of the study could be of use for human resource managers, as well as for supervisors of secretaries, in order to minimise potential stressors that could negatively affect the health of secretaries.

\section{Conceptual framework}

The conceptual framework for the study was Lazarus's transactional stress theory (Lazarus, 1999; Lazarus \& Folkman, 1984), which is one of the most influential theories in the context of psychological stress research (Folkman \& Moskowitz, 2000). This theory appeared suitable for the study, as it is generally believed that the experience of occupational stress at individual level depends on whether a person perceives and interprets workplace conditions as stressful or not (Conard \& Matthews, 2008; Oginska-Bulik, 2005; Snelgrove, 1998; Stacciarini \& Troccoli, 2004). Lazarus's theory conceptualises stress as an outcome of a process of cognitive appraisals and coping mechanisms. According to Lazarus, people constantly appraise and evaluate what is happening to them and whether or not they are in a position to handle such a situation. Lazarus differentiates between 'primary appraisal', in which a person assesses a situation as harmful, threatening or benign and 'secondary appraisal', in which a person assesses the usefulness of the resources available to manage this situation. When there is a discrepancy between the primary and secondary appraisals, the person experiences stress. During the process of appraising, certain coping attempts contribute to 're-appraisals' of the same situation, which can reduce or increase the experience of stress and, as a result, affect psychological wellbeing. Based on cognitive appraisals, the same situation may cause stress for one person but not for another person. For example, sharing an office with a colleague can be a potential stressor for secretaries. However, not every secretary who has to share an office, that is, who is exposed to this potential stressor, will perceive sharing an office as stressful. While one secretary might assess sharing an office as a threat to her way of office organisation, and therefore feel stressed about it, another secretary might assess sharing an office as a welcome opportunity for social support in the workplace and will therefore not experience stress.

The way in which a person responds to a potentially stressful situation depends on how they evaluate the situation and what coping strategies they apply. Lazarus differentiates between problem-focused and emotion-focused coping strategies. Problem-focused coping strategies include proactive behaviours that target the problem directly with the intention of changing or modifying the cause of stress, while emotion-focused coping strategies attempt to restore psychological balance and wellbeing without rectifying the problem as such. In the example above, a secretary who is stressed about sharing an office might suggest to her supervisor that she have an office to herself and/or present valid reasons that could justify why she should not have to share an office (problem-focused coping). In contrast, another secretary who finds sharing an office stressful might engage in evasive behaviour (emotion-focused coping) and, for instance, try to avoid being in her office by looking for tasks that require her to be out of the office most of the time. In an attempt to restore her emotional wellbeing, she might engage in denial and try to pretend that she has no problem with sharing an office. If problem-focused coping strategies are prone to fail (e.g. in the example of sharing an office, because of a shortage of offices), the person might switch to emotionfocused coping strategies. According to Lazarus, emotionfocused coping strategies dominate in situations wherein a person feels that nothing can be done to eliminate the causes of stress. Emotion-focused coping strategies are known to be less effective in completely eliminating the experience of stress, and, as a result, stress negatively affects psychological and physiological wellbeing.

In line with Lazarus's theory, this study regarded it as important to differentiate between exposure to potential stressors and subjective stress experience. It was expected that mere exposure to potential stressors would not affect psychophysical wellbeing, but that the subjective stress experience would negatively affect wellbeing.

\section{RESEARCH DESIGN}

\section{Research approach}

The nature of the study was exploratory and descriptive within the quantitative research paradigm, using a cross-sectional survey method and correlational analysis. Prior to the study, and considering the lack of research on stress experienced by secretaries, a non-directive focus group discussion was held with a small group of five selected secretaries from different employment levels and divisions within the University of Botswana. The aim of the discussion was to gain insight into what secretaries might perceive as common work-related stressors. The information obtained from the discussion was used for the formulation of statements for a questionnaire that was developed for the purpose of this study. The questionnaire was distributed among all secretaries within the University of Botswana.

\section{Data collection \\ Research participants}

The self-administered questionnaire, together with a return envelope addressed to one of the researchers, was sent via mail 
to all the secretaries listed in the University's internal telephone directory. Participation in the study was voluntary and anonymous. Of the 146 secretaries who were approached, 64 returned their questionnaires, giving a response rate of $43.8 \%$. The age of the respondents ranged from 21 to 50 years, with an average of 37 years (median). The respondents had worked at the university for between 3 months and 23 years; on average, the respondents had worked at the university for 11 years and 8 months (median). Most of them (70.3\%) had worked elsewhere before joining the university. The majority of the respondents $(77.4 \%)$ were placed in an academic department or faculty office, $8.1 \%$ in a support centre and $14.5 \%$ in administration. In terms of rank, $46.0 \%$ held the position of 'secretary', $39.7 \%$ of 'personal secretary' and $14.3 \%$ of 'personal assistant'.

\section{Measuring instrument}

The main variables contained in the questionnaire and analysed for the purpose of this study were occupational stress and psychosomatic complaints. Occupational stress was operationalised through 17 statements resulting from the focus group discussion and referring to the extent to which a given aspect of work bothered the respondent. The aspects of work that were specified included ambiguity in job expectation, reduced competencies, working overtime, sharing resources, lack of recognition and limited opportunity for promotion. Each statement started with the phrase 'It bothers me that ...' (e.g. 'It bothers me that I have to do work that is not part of my job description', '... that I have to share a telephone with a colleague', '... that my supervisor does the work that I am supposed to do' and '... that secretaries cannot be promoted to the level of administrative officer'). All statements were presented with a Likert-type rating scale (i.e. 'very much', 'much', 'not sure', 'not much', 'not at all') as well as with the answer category 'not applicable'. The latter was presented for respondents who were not exposed to the potential stressors. As mentioned above and considering that potential stressors are not necessarily perceived as stressful at the subjective level, in this study it was regarded as important to differentiate between 'exposure to potential stressors' and 'subjective stress experience'. Responses within the categories 'very much' to 'not at all' were interpreted as 'exposure to potential stressor', but only responses within the categories 'very much' or 'much' were interpreted as indicators of 'subjective stress experience'. Nine questions probed psychosomatic complaints (e.g. headaches, digestive problems, insomnia, exhaustion or fatigue) and the frequency of their occurrence, based on selfreported assessment.

To obtain work-related information about the respondents, the questionnaire also contained the variables workload, job satisfaction, career expectations and personal background. Workload was operationalised through four statements referring to the amount of work from the respondents' point of view (e.g. 'The amount of work I have to do is just too much' and 'There are times when I have nothing to do'). Three answer categories were provided: 'often', 'sometimes' and 'never'. Job satisfaction was operationalised through five statements referring to satisfaction with secretarial work, productiveness, salary, chances of promotion and relationship with supervisor; answer categories provided were 'true', 'not sure' and 'false'. Four statements targeted career expectations (e.g. 'When I joined the University I expected to be sent for staff development'). Personal background variables explored age, employment position (i.e. 'secretary', 'personal secretary' or 'personal assistant'), division of employment (i.e. academic faculty or department, academic service centre, university administration) and length of employment at the University of Botswana. Gender was not considered because it was known to the researchers that all but one of the university's secretaries were female.

\section{Statistical analysis}

Data obtained from the questionnaires were analysed with SPSS (version 16.0), using descriptive statistics and correlational analysis. Spearman's rho was used to identify significant associations between the stress variables and psychosomatic complaints. For descriptive purposes, possible associations with psychosomatic complaints were also explored for the remaining variables of workload, job satisfaction, career expectations and personal background. To determine whether these associations were statistically significant, the $5 \%$ significance level $(p=0.05)$ was used.

TABLE

Potential stressors and subjective stress experience

\begin{tabular}{|c|c|c|c|c|c|}
\hline \multirow[t]{2}{*}{ Stressor categories } & \multirow[t]{2}{*}{ Stressors } & \multicolumn{2}{|c|}{$\begin{array}{l}\text { Stressor applicable or exposure } \\
\text { to stressor }\end{array}$} & \multicolumn{2}{|c|}{$\begin{array}{l}\text { Subjectively perceived as } \\
\text { stressful }\end{array}$} \\
\hline & & $N$ & $\%$ & $N$ & $\%$ \\
\hline \multirow[t]{4}{*}{ Ambiguity in job expectation } & - doing work that is not part of job description & 57 & 89.1 & 22 & 38.6 \\
\hline & - lack of job clarity between colleagues & 44 & 68.8 & 24 & 54.6 \\
\hline & - acting in a higher position without allowance & 46 & 71.9 & 29 & 63.0 \\
\hline & - junior colleague does not want to be supervised & 38 & 59.4 & 15 & 23.8 \\
\hline \multirow[t]{3}{*}{ Reduced competencies } & - supervisor does the work of the secretary & 55 & 85.9 & 34 & 61.8 \\
\hline & - administrators absorb secretarial work & 53 & 82.8 & 28 & 52.8 \\
\hline & - not permitted to take minutes in meetings & 60 & 93.8 & 33 & 55.0 \\
\hline Working overtime & - having to work overtime & 51 & 79.7 & 6 & 11.8 \\
\hline \multirow[t]{3}{*}{ Sharing resources } & - having to share an office & 52 & 81.2 & 21 & 40.4 \\
\hline & - having to share a telephone & 50 & 78.1 & 17 & 34.0 \\
\hline & - having to share a computer & 47 & 73.4 & 26 & 55.3 \\
\hline \multirow[t]{4}{*}{ Lack of recognition } & - capability is not recognised & 55 & 85.9 & 45 & 81.8 \\
\hline & - experience is not acknowledged & 56 & 87.5 & 49 & 87.5 \\
\hline & $\begin{array}{l}\text { - people in higher positions receive more respect than } \\
\text { secretaries }\end{array}$ & 59 & 92.2 & 37 & 62.8 \\
\hline & - secretaries are excluded from public functions & 63 & 98.4 & 42 & 66.7 \\
\hline \multirow[t]{2}{*}{ Limited opportunity for promotion } & - cannot be promoted to the level of administrative officer & 63 & 98.4 & 56 & 88.8 \\
\hline & - administrative assistants get promoted faster & 62 & 96.9 & 55 & 88.7 \\
\hline
\end{tabular}




\section{RESULTS}

The results revealed that, overall, the respondents were satisfied with their job; $68.9 \%$ liked the kind of work they did, $89.1 \%$ felt productive at work and $89.1 \%$ reported having a good relationship with their supervisor. However, $65.6 \%$ felt that they were not paid a fair salary and $62.9 \%$ were not satisfied with their chances for promotion. In terms of workload, only $15.6 \%$ of the respondents felt that the amount of work was too much while $54.7 \%$ reported that 'sometimes' they had nothing to do. A relatively high number of $67.2 \%$ respondents reported that 'sometimes' they felt quite bored at work and 68.3\% 'sometimes' wished that they had more work to do.

Table 1 shows the exposure to and subjective experience of the stressors investigated. Most of the respondents were exposed to the various potential stressors; however, not all of them experienced these stressors as being stressful. In total, $89.1 \%$ of the respondents reported that they performed work that was not part of their job description, but only $38.6 \%$ of them were bothered 'much' or 'very much' by this situation. Some $68.8 \%$ of the respondents reported that they lacked job clarity, which was stressful to $54.6 \%$ of them. More information on this matter revealed that many of the respondents felt that they were doing the work of a messenger $(70.3 \%)$, an office assistant $(57.8 \%)$, or a 'tea lady' (39.1\%).

As is further evident from Table 1, 71.9\% of the respondents had acted in higher positions (i.e. as 'personal secretary' or 'personal assistant') without receiving an acting allowance, which was stressful to $63.0 \%$. Some $59.4 \%$ of the respondents reported that they had to supervise junior colleagues who did not want to be supervised by them, which was stressful to $23.8 \%$ of the respondents. Most of the respondents felt that their competencies had been reduced over the years. More specifically, $85.9 \%$ of the respondents reported that their supervisors performed work that secretaries were supposed to do, which was stressful to $61.8 \%$. Similarly, $82.8 \%$ of the respondents indicated that faculty administrators had absorbed their work, which was experienced as stressful by $52.8 \%$. Not being permitted to take minutes during meetings applied to $93.8 \%$ and was stressful to $55.0 \%$. At the University of Botswana, minutes are usually taken by faculty administrators or academic staff members, who may then ask secretaries to type the minutes. During the focus group discussion it was revealed that the secretaries felt that the University did not want them to hear what was discussed in meetings, '... but ...' - the discussants added with resentment - '... we are expected to type the minutes'.

Working overtime apparently applied to $79.7 \%$ of the respondents, but only $11.8 \%$ of them experienced this as stressful. Most of the respondents had to share an office (81.2\%), a telephone $(78.1 \%)$ and a computer $(73.4 \%)$. Sharing a computer was perceived as stressful by $55.3 \%$, sharing an office was stressful to $40.4 \%$ and sharing a telephone was stressful to $34.0 \%$ of the respondents.

The stressor categories referring to recognition and promotion resulted in the highest percentages of subjective stress
(Table 1). Most of the respondents experienced stress because they felt that their capabilities were not recognised $(81.8 \%)$, that their experience was not acknowledged (87.5\%), that people in higher positions received more respect than secretaries $(62.8 \%)$, and that secretaries were excluded from public functions at the university (66.7\%). During the focus group discussion, one of the secretaries narrated with emphasis: 'We are the forgotten ones'. It was stressful to even more respondents that secretaries could not be promoted to the level of administrative officer $(88.8 \%)$ and that administrative assistants were apparently promoted faster than secretaries $(88.7 \%)$.

In addition to what is presented in Table 1 and also of interest in the stressor 'promotion', $63.5 \%$ of the respondents reported that their hopes for promotion had faded away. Regarding the respondents' career expectations, it was found that, at the time when they joined the university, a substantive number of them had expected to become an administration officer (48.4\%), to be sent for staff development (54.7\%) and/or to study for a degree $(40.6 \%)$. The great majority of respondents $(84.4 \%)$ would have liked to receive more training in secretarial skills.

Table 2 shows the frequency of psychosomatic complaints as reported by the respondents. Few respondents reported experiencing the psychosomatic symptoms 'often', except for headaches $(22.6 \%)$. However, a high proportion of the respondents experienced the various psychosomatic problems 'sometimes', with exhaustion and fatigue leading the list of complaints $(75.0 \%)$, followed by headaches $(62.9 \%)$, digestive problems (62.5\%) and stomach aches (62.5\%).

Most stressors were associated with various psychosomatic complaints, although only at a modest to moderate level (Table 3). The following stressors did not correlate with any of the psychosomatic complaints at the 0.05 significance level and are therefore not listed in Table 3: 'supervisor does secretarial work', 'faculty administrators absorbed secretarial work', 'capability is not recognised', 'experience is not acknowledged' and 'administrative assistants get promoted faster'.

Surprisingly, in some cases the mere exposure to certain potential stressors (i.e. lack of job clarity, supervising junior colleagues, sharing a telephone and sharing a computer) was associated with psychosomatic problems, regardless of whether these stressors were subjectively perceived as stressful or not (Table 3). Compared to respondents who were not exposed to a lack of job clarity, the respondents who were exposed to it were significantly more likely to report headaches, throat problems or tonsillitis, insomnia, exhaustion or fatigue and nervousness. Respondents who reported that they had junior colleagues who did not want to be supervised by them were more likely to report insomnia and digestive problems. Sharing a telephone as well as sharing a computer was associated with headaches (Table 3).

The remaining stressors correlated with psychosomatic complaints only once the respondents perceived these stressors as stressful (Table 3). Most of the stressors were associated with

TABLE 2

Self-reported frequency of psychosomatic complaints

\begin{tabular}{|c|c|c|c|c|c|c|c|}
\hline \multirow[t]{2}{*}{ Psychosomatic complaints } & \multicolumn{2}{|c|}{ Often } & \multicolumn{2}{|c|}{ Sometimes } & \multicolumn{2}{|c|}{ Never } & \multirow{2}{*}{$\frac{\text { Total }}{N}$} \\
\hline & $N$ & $\%$ & $N$ & $\%$ & $N$ & $\%$ & \\
\hline Headaches & 14 & 22.6 & 39 & 62.9 & 9 & 14.5 & 62 \\
\hline High blood pressure & 4 & 6.3 & 20 & 31.7 & 39 & 61.9 & 63 \\
\hline Cardiac problems & 1 & 1.6 & 16 & 25.8 & 45 & 72.6 & 62 \\
\hline Stomach aches & 2 & 3.1 & 40 & 62.5 & 22 & 34.4 & 64 \\
\hline Throat problems or tonsillitis & 2 & 3.1 & 26 & 40.6 & 36 & 56.3 & 64 \\
\hline Digestive problems & 2 & 3.1 & 40 & 62.5 & 22 & 34.4 & 64 \\
\hline Insomnia & 7 & 11.1 & 36 & 57.1 & 20 & 31.7 & 63 \\
\hline Exhaustion and fatigue & 6 & 9.4 & 48 & 75.0 & 10 & 15.6 & 64 \\
\hline Nervousness & 7 & 11.1 & 39 & 61.9 & 17 & 27.0 & 63 \\
\hline
\end{tabular}


TABLE 3

Exposure to potential stressors, subjective experience of potential stressors as stressful, and psychosomatic complaints

\begin{tabular}{|c|c|c|c|c|c|c|c|c|c|}
\hline Categories & Stressors & & Headaches & $\begin{array}{l}\text { Cardiac } \\
\text { problems }\end{array}$ & $\begin{array}{l}\text { Throat } \\
\text { problems }\end{array}$ & Insomnia & $\begin{array}{l}\text { Exhaustion } \\
\text { or fatigue }\end{array}$ & Nervousness & $\begin{array}{l}\text { Digestive } \\
\text { problems }\end{array}$ \\
\hline \multirow{8}{*}{$\begin{array}{l}\text { Ambiguity in job } \\
\text { expectation }\end{array}$} & \multirow{2}{*}{$\begin{array}{l}\text { doing work that is not } \\
\text { part of job description }\end{array}$} & exposure & ns & ns & ns & ns & ns & ns & ns \\
\hline & & stressful & $r=0.306^{*}$ & ns & $r=0.264^{*}$ & ns & ns & ns & ns \\
\hline & \multirow{2}{*}{$\begin{array}{l}\text { lack of job clarity between } \\
\text { colleagues }\end{array}$} & exposure & $r=0.268^{*}$ & ns & $r=0.328^{* *}$ & $r=0.273^{*}$ & $r=0.323^{* *}$ & $r=0.281^{*}$ & ns \\
\hline & & stressful & ns & ns & ns & ns & ns & ns & ns \\
\hline & \multirow{2}{*}{$\begin{array}{l}\text { acting in a higher position } \\
\text { without allowance }\end{array}$} & exposure & ns & ns & ns & ns & ns & ns & ns \\
\hline & & stressful & $r=0.382^{* *}$ & $r=0.332^{*}$ & ns & ns & ns & ns & ns \\
\hline & \multirow{2}{*}{$\begin{array}{l}\text { junior colleague does not want } \\
\text { to be supervised }\end{array}$} & exposure & ns & ns & ns & $r=0.461^{* * *}$ & ns & ns & $r=0.291^{*}$ \\
\hline & & stressful & ns & ns & ns & ns & ns & ns & ns \\
\hline \multirow{2}{*}{$\begin{array}{l}\text { Reduced } \\
\text { competencies }\end{array}$} & \multirow{2}{*}{$\begin{array}{l}\text { not permitted to take minutes } \\
\text { in meetings }\end{array}$} & exposure & ns & ns & ns & ns & ns & ns & ns \\
\hline & & stressful & $r=0.260^{*}$ & ns & ns & ns & ns & ns & ns \\
\hline \multirow{2}{*}{$\begin{array}{l}\text { Working } \\
\text { overtime }\end{array}$} & \multirow[t]{2}{*}{ having to work overtime } & exposure & ns & ns & ns & ns & ns & ns & ns \\
\hline & & stressful & $r=0.303^{*}$ & ns & ns & ns & $r=0.438^{\star \star \star}$ & ns & ns \\
\hline \multirow{6}{*}{$\begin{array}{l}\text { Sharing } \\
\text { resources }\end{array}$} & \multirow[t]{2}{*}{ having to share an office } & exposure & ns & ns & ns & ns & ns & ns & ns \\
\hline & & stressful & $r=0.378^{* *}$ & $r=0.318^{*}$ & $r=0.324^{*}$ & ns & ns & $r=0.321^{*}$ & ns \\
\hline & \multirow{2}{*}{$\begin{array}{l}\text { having to share a } \\
\text { telephone }\end{array}$} & exposure & $r=0.262^{*}$ & ns & ns & ns & ns & ns & ns \\
\hline & & stressful & $r=0.379^{* *}$ & ns & ns & ns & ns & ns & ns \\
\hline & \multirow{2}{*}{$\begin{array}{l}\text { having to share a } \\
\text { computer }\end{array}$} & exposure & $r=0.258^{*}$ & ns & ns & ns & ns & ns & ns \\
\hline & & stressful & ns & ns & $r=0.287^{\star}$ & ns & ns & ns & $r=0.347^{*}$ \\
\hline \multirow{4}{*}{$\begin{array}{l}\text { Lack of } \\
\text { recognition }\end{array}$} & \multirow{2}{*}{$\begin{array}{l}\text { people in higher positions } \\
\text { receive more respect }\end{array}$} & exposure & ns & ns & ns & ns & ns & ns & ns \\
\hline & & stressful & ns & ns & ns & ns & ns & ns & $r=0.304^{*}$ \\
\hline & \multirow{2}{*}{$\begin{array}{l}\text { excluded from public } \\
\text { functions }\end{array}$} & exposure & ns & ns & ns & ns & ns & ns & ns \\
\hline & & stressful & ns & ns & ns & ns & ns & ns & $r=0.283^{*}$ \\
\hline \multirow{2}{*}{$\begin{array}{l}\text { Limited opportunity } \\
\text { for promotion }\end{array}$} & \multirow{2}{*}{$\begin{array}{l}\text { cannot be promoted to level } \\
\text { of administrative officer }\end{array}$} & exposure & ns & ns & ns & ns & ns & ns & ns \\
\hline & & stressful & ns & ns & ns & ns & ns & ns & $r=0.277^{*}$ \\
\hline
\end{tabular}

ot significant; $r$, Spearman's rh

${ }^{*} p \leq 0.05 ;{ }^{* *} p \leq 0.01 ;{ }^{* *} p \leq 0.001$

more than one psychosomatic complaint at the 0.05 significance level. Headaches were associated with most of the stressors. More specifically, respondents who perceived doing work that was not part of their job description as stressful were more likely to report headaches and throat problems or tonsillitis. Respondents who perceived acting in a higher position without receiving an acting allowance as stressful were also more likely to report headaches as well as cardiac problems. At the subjective level, (1) not being allowed to take minutes during meetings was also associated with headaches, (2) working overtime was associated with headaches and exhaustion or fatigue, (3) sharing an office was associated with headaches, cardiac problems, throat problems and nervousness, (4) sharing a telephone was associated with headaches and (5) sharing a computer was associated with throat problems or tonsillitis and digestive problems. Digestive problems were also associated with perceptions regarding respect, public functions and promotion (Table 3). None of the stressors was associated with high blood pressure and stomach problems at the 0.05 significance level.

Further analysis with regard to career expectations revealed that respondents who had expected to be sent for staff development were more likely to report headaches $(r=0.289, p=0.042)$. Respondents who had expected to become administration officers were more likely to report high blood pressure $(r=0.338, p=0.007)$, insomnia $(r=0.322$, $p=0.010)$ and nervousness $(r=0.310, p=0.013)$. None of the variables measuring job satisfaction and workload correlated significantly with any of the psychosomatic complaints, except for boredom: respondents who felt bored at work were more likely to report exhaustion or fatigue $(r=0.255, p=0.042)$. Age as a potential predictor of health problems did not correlate with any of the psychosomatic complaints, except for high blood pressure; that is, the age group 41-50 years was significantly more likely to report problems with high blood pressure $(r=-0.414, p=0.001)$. None of the other personal background variables was significantly associated with psychosomatic complaints.

\section{DISCUSSION}

The study aimed to explore occupational stressors in the secretarial profession and to investigate whether these stressors were associated with psycho-physiological wellbeing. The study identified 17 potential stressors pertaining to ambiguity in job expectation, reduced competencies, working overtime, sharing resources, lack of recognition and limited opportunities for promotion. The various stressors applied to most of the secretaries, but not all of them perceived the stressors as stressful.

Unlike what was found in other research on secretaries, in this study promotion was identified as a major stressor. At the University of Botswana, the career path for secretaries foresees promotion from 'secretary' to 'personal secretary' to 'personal assistant'; many secretaries remain 'stuck' at secretary and personal secretary levels. In spite of this career path, almost half of the sample had expected to join the administrative sector and to be promoted to administrative officers when they joined the university and, interestingly, they had maintained these expectations for many years. The discrepancy between the secretaries' career expectations and their career outcome helps to explain why promotion was found in this study to be a major stressor. The findings also indicate that there might be a need for human resources managers at the University of 
Botswana who are involved in the process of recruitment and appointment of secretaries to clarify career opportunities before an employment agreement is signed; in this way, ongoing stress caused by incorrect expectations regarding promotion could have been avoided.

As also found in previous studies (Herrting et al., 2003; Michailidis \& Asimenos, 2001; Snow et al., 2003), lack of recognition was a major stressor for the secretaries in this study. Perceived lack of recognition can cause employees to believe that their contributions are not valued or appreciated, that they are not respected, or that they are disposable (Harkness et al. 2005) and therefore cause stress. Such beliefs were confirmed in this study. In the context of recognition, another stressor identified in this study (but not mentioned in other studies) that requires attention is that of acting in higher positions (i.e. as a personal secretary or personal assistant) without receiving an acting allowance. Being asked to act in a higher position could be perceived as a form of recognition of one's experience and capabilities. However, not being rewarded for performing work at a higher level can undermine the effects of recognition and therefore produce stress. Although employees do not always expect rewards of a financial nature (Cascio, 2003) this study found that the lack of an acting allowance probably reinforced the secretaries' perceptions that their work was not appreciated by the university. Interestingly, the respondents who felt stressed as a result of not being paid an acting allowance were significantly more likely to report headaches and cardiac problems, which could be interpreted as indicators of suppressed anger (Byrne \& Espnes, 2008; Haynes \& Feinleib, 1980).

Acting in a higher position also means performing work that is not part of one's job description, which turned out to be another important stressor in this study. Most of the respondents reported that they performed tasks that were not part of their job description. At the same time, the respondents felt that the university had reduced their competencies, such as, for example, taking minutes in meetings. These findings are connected to a lack of job clarity. While there might have been misconceptions among the secretaries as to why they were, for instance, not permitted to take minutes, stress could probably have been avoided if the university had clarified to them through its human resources section why it preferred administrators and academics to take minutes instead of secretaries.

While some studies have identified the secretary-supervisor relationship as a stressor (Michailidis \& Asimenos, 2001; Peeters et al., 1995), this study found that most of the secretaries assessed the relationship with their supervisor as good. However, almost two thirds of the respondents were stressed by the feeling that their supervisors apparently performed tasks that secretaries were supposed to do. This is an important finding with implications for human resource management and the job portfolios of secretaries. Over the past three decades, computerisation and office automation have changed the workplace of secretaries drastically. With the advent of the personal computer, managers started performing increasingly more of the tasks and routines that were earlier done by secretaries (Dolan \& Tziner, 1988; Seppala, 2001). As a result, secretaries may feel 'pruned' in their importance and value to their supervisors. Although work organisations usually embrace rapid developments in communication and information technology, human resource managers might sometimes overlook the need to adjust job descriptions to new developments on a regular basis. The job descriptions of secretaries, in particular, might need to be revisited in order to assign meaningful tasks to them. Such need might apply in the case of the secretaries in this study.

The findings of this study show that a substantive number of secretaries reported boredom and wished that they had more work to do, which indicates that their services were underutilised. Interestingly, secretaries who experienced boredom were significantly more likely to report exhaustion or fatigue than secretaries who did not experience boredom. Such finding can be explained by the fact that spending many hours at work without having much to do is tiresome and stressful in itself (Plattner, 1993).

While boredom can cause stress, long working hours can also cause stress (Dickinson \& Wright, 2008). Surprisingly, only a few respondents felt stressed about working overtime. Perhaps the secretaries in this study felt that being asked to work overtime gave them a sense of being needed, which could have served as compensation for the perceived lack of recognition. But, in line with other studies (e.g. Tucker \& Rutherford, 2005), those respondents who felt stressed about working overtime were significantly more likely to report headaches and exhaustion or fatigue.

Based on Lazarus's stress theory (Lazarus, 1999), it was expected that only those respondents who perceived potential stressors as stressful would have been affected negatively in their psychosomatic wellbeing. This expectation was confirmed for most stressors, but, unexpectedly, some stressors were associated with psychosomatic complaints regardless of whether or not the respondents perceived them as stressful. One of these stressors was sharing a telephone. The importance a telephone holds for secretaries could be worth further investigation. It is possible that the telephone enables secretaries to maintain social contacts with colleagues, friends or family members who can provide them with social support during working hours. As confirmed in other studies, social support and the opportunity to talk to others can have stressrelieving effects (Fenlason \& Beehr, 1994; Snow et al., 2003). Therefore, having to share a telephone, even if not perceived as stressful, could affect psychological wellbeing negatively as it restricts access to one's social support system.

The mere exposure to a lack of job clarity was associated with more psychosomatic complaints than any other stressor, regardless of feelings of stress. In addition, secretaries who reported that they had junior colleagues who did not want to be supervised by them were significantly more likely to suffer from digestive problems and insomnia, regardless of whether or not they perceived this situation as stressful. As revealed by cross-tabulations, several respondents at the lowest rank of 'secretary' reported that they had to supervise junior colleagues, although there was no lower level than 'secretary'. It appears that, possibly based on age or length of employment at the university, they perceived certain colleagues as junior and simply assumed that they would have to supervise them, whereas the 'junior' colleagues might rightfully not have accepted their colleagues as their supervisors. Such findings indicate a need for human resource management to produce clearly outlined and unambiguous job descriptions and allocations of tasks and duties that do not leave space for misinterpretation. Well-designed job descriptions are known to foster beneficial teamwork and cooperation (Furnham, 2005), while lack of job clarity and the related role ambiguity affect collaboration negatively and lead to tension and therefore stress at the workplace (Spector, 2003).

Considering that this study found that mere exposure to the stressors 'lack of job clarity' and 'supervision of junior colleagues' was associated with psychosomatic complaints, regardless of whether or not the respondents perceived these stressors as stressful, it is possible that these respondents used emotion-focused coping strategies. As mentioned above, emotion-focused coping strategies dominate in situations where a person feels that nothing can be done to eliminate the causes of stress (Lazarus, 1999). Considering that job clarity among colleagues depends on clearly defined job descriptions provided by human resource management, secretaries have 
little or no control over this stressor. In the attempt to restore their emotional balance, several of the respondents might have engaged in denial and tried to convince themselves that the lack of job clarity and working with junior colleagues was not stressful to them, although this was not effective enough to stop the stressors from 'nagging' at their psychosomatic wellbeing (see also Akerstedt et al., 2002).

\section{Limitations and recommendations}

This study has several limitations. Firstly, the findings might only apply to the specific work context of the University of Botswana. Secondly, the response rate of $43.8 \%$ could have resulted in an unrepresentative sample, which would limit the extent to which the findings of this study could be generalised. Thirdly, although the study revealed that most stressors were associated with psychosomatic complaints, the statistical analysis used in this study does not allow conclusions about causal relationships between these variables to be drawn. The data analysis did not control for intervening and moderating variables that could have contributed to the psychosomatic complaints; the modest to moderate correlations obtained suggest that other variables that were not controlled for must have contributed to the complaints. Fourthly, the results are based on self-reporting, which reduces the reliability of the findings with regard to exposure to potential stressors and the prevalence and severity of the psychosomatic complaints. Fifthly, the study only explored potential stressors and subjective stress experience and did not investigate what coping strategies the secretaries used to deal with their stress. More in-depth research would be necessary to address these limitations. In addition, considering that the secretaries in this study worked in an academic institution, the results might not necessarily apply to work organisations that differ from the work context of a university. Additional research would be necessary to compare various work contexts and organisationspecific work environments and to investigate their relevance to occupational stress and health among secretaries.

\section{CONCLUSION}

In spite of the limitations of this study and the need for further research, the results provide some insight into occupational stress among secretaries and demonstrate that job stress can interfere with their psycho-physiological wellbeing. The stressors identified in this study might appear to be simple daily hassles of secretaries, but daily hassles are known to contribute more to psycho-physiological problems than major life events (Sanderson, 2004). The findings of this study show that even when employees perceive certain stressors as not being stressful, mere exposure to a potential stressor can still affect a person's wellbeing. In other words, if a potential stressor exists in the work environment, it can contribute to psychosomatic ailments. It is important to note that, for most of the stressors identified in this study, proactive coping at the secretaries' level would not have been possible. Stressors such as lack of job clarity, lack of recognition, underutilising employees' capabilities and competencies and limited opportunities for promotion are managerial matters and require solutions at the organisational level, and more specifically, at the level of human resource management. Considering that the stressors identified in this study are beyond the control of secretaries, the health promotion and wellness programmes often suggested for stress management interventions (e.g. Noblet \& LaMontagne, 2006) might not be sufficient in the case of secretaries. While, for example, relaxation exercises to relieve stress might have positive effects on some secretaries, these effects might disappear rapidly once they return to their work environment. As long as there is no change in the work environment, stressors continue to work on peoples' minds (Lazarus, 1999). Therefore, in the case of the stressors identified in this study, effective stress management would have to be tied to successful human resource management.

\section{REFERENCES}

Adams, T.B., \& Cowen, V.S. (2004). Health risk factors and absenteeism among university employees. American Journal of Health Studies, 19, 129-137.

Akerstedt, T., Knutsson, A., Westerholm, P., Theorell, T., Alfredsson, L., \& Kecklund, G. (2002). Sleep disturbances, work stress and work hours. A cross-sectional study. Journal of Psychosomatic Research, 53, 741-748.

Barkhuizen, N., \& Rothmann, S. (2008). Occupational stress of academic staff in South African higher education institutions. South African Journal of Psychology, 38, 321-336.

Boscolo, P., Youinou, P., Theoharides, T., Cerulli, G., \& Conti, P. (2008). Environmental and occupational stress and autoimmunity. Autoimmunity Reviews, 7, 340-343.

Byrne, D.G., \& Espnes, G.A. (2008). Occupational stress and cardiovascular disease. Stress and Health, 24, 231-238.

Cascio, W.F. (2003). Managing human resources. Productivity, quality of work life, profits. Boston: McGraw Hill.

Clarke, S.G., \& Cooper, C.L. (2000). The risk management of occupational stress. Health, Risk E Society, 2, 173-187.

Conard, M.A., \& Matthews, R.A. (2008). Modelling the stress process: Personality eclipses, dysfunctional cognitions and workload in predicting stress. Personality $\mathcal{E}$ Individual Differences, 44, 171-181.

Cottrell, S. (2001). Occupational stress and job satisfaction in mental health nursing: Focused interventions through evidence-based assessment. Journal of Psychiatric and Mental Health Nursing, 8, 157-164.

Demongeot, C. (1986). Secretaries: The unrecognized members of the management team. Training $\mathcal{E}$ Development Journal, 40 28-29.

Dickinson, T., \& Wright, K.M. (2008). Stress and burnout in forensic mental health nursing: A literature review. British Journal of Nursing, 17, 82-87.

Dolan, S., \& Tziner, A. (1988). Implementing computer-based automation in the office: A study of experienced stress. Journal of Organizational Behavior, 9, 183-187.

Farmer, R., Clancy, C., Oyefeso, A., \& Rassool, H.G. (2002). Stress and work with substance misusers: The development and cross-validation of a new instrument to measure staff stress. Drugs: Education, Prevention and Policy, 9, 377-388.

Fenlason, K.J., \& Beehr, T.A. (1994). Social support and occupational stress: Effects of talking to others. Journal of Organizational Behavior, 15, 157-175.

Flam, H. (2002). Corporate emotions and emotions in corporations. In J. Barbalet (Ed.), Emotions and sociology, (pp. 90-112). Malden, US: Blackwell Publishing.

Folkman, S., \& Moskowitz, J.T. (2000). Stress, positive emotion, and coping. Current Directions in Psychological Science, 9, 115-118.

Furnham, A. (2005). The psychology of behavior at work. Hove: Psychology Press.

Garrison, R., \& Eaton, W.W. (1992). Secretaries, depression and absenteeism. Women $\mathcal{E}$ Health, 18, 53-76.

Halpern, D.F. (2005). Psychology at the intersection of work and family: Recommendations for employers, working families, and policymakers. American Psychologist, 60, 397-409.

Hardy, G.E., Woods, D., \& Wall, T.D. (2003). The impact of psychological distress on absence from work. Journal of Applied Psychology, 88, 306-314.

Harkness, A.M., Long, B.C., Bermbach, N., Patterson, K., Jordan, S., \& Kahn, H. (2005). Talking about work stress: Discourse analysis and implications for stress interventions. Work Stress, 19, 121-136.

Haynes, S.G., \& Feinleib, M. (1980). Women, work and coronary heart disease: Prospective findings from the Framingham heart study. American Journal of Public Health, 70, 133-141.

Hendel, D.D., \& Horn, A.S. (2008). The relationship between academic life conditions and perceived sources of faculty stress over time. Journal of Human Behavior in the Social Environment, 17, 61-88.

Herrting, A., Nilsson, K., Theorell, T., \& Larsson, U.S. (2003) Personnel reductions and structural changes in health care. Work-life experiences of medical secretaries. Journal of Psychosomatic Research, 54, 161-170. 
Jacobs, P.A., Tytherleigh, M.Y., Webb, C., \& Cooper, C.L. (2007) Predictors of work performance among higher education employees: An examination using the ASSET model of stress. International Journal of Stress Management, 14, 199-210.

Lazarus, R.S. (1999). Stress and emotion: A new synthesis. London: Free Association Books.

Lazarus, R.S., \& Folkman, S. (1984). Stress, appraisal and coping. New York: Springer.

Lindorff, M. (2000). Is it better to perceive than to receive? Social support, stress and strain for managers. Health $\mathcal{E}$ Medicine, 5, 271-286.

Malach-Pines, A. (2002). The burnout measure, short version. International Journal of Stress Management, 12(1), 78-88.

Michailidis, M.P., \& Asimenos, A. (2001). Occupational stress as it relates to higher education, individuals and organizations. Work, 19, 137-147.

Murta, S.G., Sanderson, K., \& Oldenburg, B. (2008). Process evaluation in occupational stress management programs: A systematic approach. American Journal of Health Promotion, $21,248-254$

Noblet, A., \& LaMontagne, A.D. (2006). The role of workplace health promotion in addressing job stress. Health Promotion International, 21, 346-353.

Oginska-Bulik, N. (2005). Emotional intelligence in the workplace: Exploring its effects on occupational stress and health outcomes in human service workers. International Journal of Occupational Medicine and Environmental Health, 18, 167-175.

Ortega, A., Brenner, S.-O., \& Leather, P. (2007). Occupational stress, coping and personality in the police: An SEM study. International Journal of Police Science E Management, 9, 36-50.

Peeters, M.C., Buunk, B.P., \& Schaufeli, W.B. (1995). A microanalysis exploration of the cognitive appraisal of daily stressful events at work: The role of controllability. Anxiety, Stress \& Coping: An International Journal, 8, 127-139.

Peltzer, K., Mashego, T.A., \& Mabeba, M. (2003). Short communication: Occupational stress and burnout among South African medical practitioners. Stress and Health, 19, 275-280.

Plattner, I.E. (1993). Zeitstress [Time stress]. Munich: Koesel.

Sadeh, A., Keinan, G., \& Daon, K. (2004). Effects of stress on sleep: The moderating role of coping style. Health Psychology, $23,542-545$.
Sanderson, C.A. (2004). Health psychology. Hoboken: Wiley.

Segerstrom, S.C., \& Miller, G.E. (2004). Psychological stress and the human immune system: A meta-analytic study of 30 years of inquiry. Psychological Bulletin, 130, 601-630.

Seppala, P. (2001). Experience of stress, musculoskeletal discomfort, and eyestrain in computer-based office work: A study on municipal workers. International Journal of Human Computer Interaction, 13, 279-304.

Snelgrove, S.R. (1998). Occupational stress and job satisfaction: A comparative study of health visitors, district nurses and community psychiatric nurses. Journal of Nursing Management, 6, 97-104.

Snow, D.L., Swan, S.C., Raghavan, C., Connell, C.M., \& Klein, I. (2003). The relationship of work stressors, coping and social support to psychological symptoms among female secretarial employees. Work \& Stress, 17, 241-263.

Spector, P.E. (2003). Industrial and organizational psychology: Research practice. Hoboken: Wiley.

Stacciarini, J.R., \& Troccoli, B.T. (2004). Occupational stress and constructive thinking: Health and job satisfaction. Journal of Advanced Nursing, 46, 480-487.

Stein, F. (2001). Occupational stress, relaxation therapies, exercise and biofeedback. Work, 17, 235-245.

Tucker, P., \& Rutherford, C. (2005). Moderators of the relationship between long work hours and health. Journal of Occupational Health Psychology, 10, 465-476.

Tytherleigh, M.Y., Jacobs, P.A., Webb, C., Ricketts, C., \& Cooper, C. (2007). Gender, health and stress in English university staff - exposure or vulnerability? Applied Psychology: An International Review, 56, 267-287.

Van Dierendonck, D., Garssen, B., \& Visser, A. (2005). Burnout prevention through personal growth. International Journal of Stress Management, 12, 62-77.

Williams, N. (2003). Occupational stress. Practice Nurse, 26, 21-26.

Zurlo, M.C., Pes, D., \& Cooper, C.L. (2007). Stress in teaching A study of occupational stress and its determinants among Italian schoolteachers. Stress $\mathcal{E}$ Health: Journal of the International Society for the Investigation of Stress, 23, 231-241. 